\title{
Meta-análise da digestibilidade ileal de aminoácidos e minerais em suínos alimentados com dietas contendo enzimas
}

\author{
Cheila Roberta Lehnen(1), Paulo Alberto Lovatto(1), Ines Andretta(1), Marcos Kipper(1), \\ Luciano Hauschild ${ }^{(2)}$ e Carlos Augusto Rossi ${ }^{(1)}$
}

\begin{abstract}
(1)Universidade Federal de Santa Maria, Departamento de Zootecnia, Avenida Roraima, no 1.000, Bairro Camobi CEP 97105-900 Santa Maria, RS.

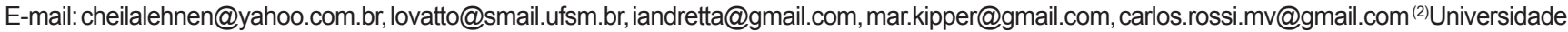
Estadual Paulista, Faculdade de Ciências Agrárias e Veterinárias, Via de Acesso Prof. Paulo Donato Castellane, s/no CEP 14884-900 Jaboticabal, SP. E-mail: Ihauschild@gmail.com
\end{abstract}

\begin{abstract}
Resumo - O objetivo deste trabalho foi avaliar, por meio da meta-análise, o efeito da fitase e da xilanase sobre a digestibilidade ileal aparente (DIa) de aminoácidos, cálcio e fósforo, em suínos em fase de crescimento. A base de dados consistiu de 21 artigos publicados entre 1998 e 2009, no total de 82 tratamentos e 644 suínos. A meta-análise foi realizada por análise gráfica, de correlação, de variância-covariância. As concentrações de fósforo fítico e as frações fibra em detergente neutro, fibra em detergente ácido e lignina em detergente ácido, nas dietas, apresentaram correlações baixas e negativas com a DIa do cálcio, fósforo e aminoácidos. A adição de fitase às dietas aumentou em $2 \%$ a DIa da arginina, em $14 \%$ a do cálcio e em $34 \%$ a do fósforo. A DIa da arginina, fenilalanina, isoleucina e lisina foi 3,3\% superior em suínos alimentados com dietas com xilanase, em relação às dietas sem a enzima. $\mathrm{O}$ fósforo fítico e as fibras, nas dietas, reduzem a DIa do cálcio, do fósforo e dos aminoácidos essenciais. O uso de fitase e xilanase, nas dietas, melhora o aproveitamento de cálcio, fósforo e alguns aminoácidos. No entanto, o excesso de cálcio e fósforo nas dietas reduz a ação da fitase sobre a digestibilidade ileal dos nutrientes.
\end{abstract}

Termos para indexação: Sus scrofa, cálcio, fitase, fósforo, nutrição, xilanase.

\section{Meta-analysis of ileal digestibility of amino acids and minerals in pigs fed diets containing enzymes}

\begin{abstract}
The objective of this study was to evaluate the effect of phytase and xylanase on the apparent ileal digestibility (aID) of amino acids, calcium and phosphorus in growing pigs through meta-analysis. The database consisted of 21 articles published between 1998 and 2009, with a total of 82 treatments and 644 pigs. A meta-analysis was performed by graphical, correlation, variance and covariance analyses. Concentrations of phytic phosphorus and the fractions neutral detergent fiber, acid detergent fiber and acid detergent lignin, in the diet, showed a low and negative correlation with aID of calcium, phosphorus and amino acids. The addition of phytase in the diets increased the aID of arginine in $2 \%$, calcium in $14 \%$ and phosphorus in $34 \%$. The aID of arginine, phenylalanine, isoleucine and lysine was 3.3\% higher in pigs fed diets containing xylanase, in comparison to the diets without the enzyme. Phytic phosphorus and fiber in the diets reduce the aID of calcium, phosphorus and essential amino acids. The use of phytase and xylanase in the diets improves the utilization of calcium, phosphorus and some amino acids. However, excessive calcium and phosphorus in the diets reduces the phytase action on the ileal digestibility of the nutrients.
\end{abstract}

Index terms: Sus scrofa, calcium, phytase, phosphorus, nutrition, xylanase.

\section{Introdução}

A composição das dietas pode interferir não só na absorção, mas também na utilização dos nutrientes pelo organismo. Em suínos, a presença de fatores antinutricionais, em especial os polissacarídeos não amiláceos (PNAs), pode influenciar a digestibilidade e a absorção dos nutrientes (Sands et al., 2009). Cerca de $75 \%$ do fósforo presente nos grãos de cereais está indisponível, em razão das ligações com moléculas de fitato. A fitase destaca-se pela efetividade na liberação do fósforo fítico das dietas (Traylor et al., 2001; Veum \& Ellersieck, 2008). Os grupos fosfato do fitato também se associam a moléculas proteicas, por meio de ligações terminais de resíduos de aspartato e glutamato, e com a participação de outros minerais (Maenz, 2001). Portanto, além de interferir na disponibilidade de fósforo, o fitato pode quelatar cátions de $\mathrm{Ca}, \mathrm{Mg}, \mathrm{Fe}, \mathrm{Zn}$ e Cu e comprometer a digestibilidade dos aminoácidos (Kies et al., 2001). Assim, em suínos, a utilização de PNAs e de P fítico é limitada pela baixa produção de enzimas específicas pelo trato gastrintestinal (Nortey

Pesq. agropec. bras., Brasília, v.46, n.4, p.438-445, abr. 2011 
et al., 2007, 2008). A xilanase, por sua vez, atua sobre as frações de fibra da dieta, das quais a celulose e a hemicelulose são as principais fontes de substrato para esta enzima (Barrera et al., 2004). Esses componentes fibrosos são responsáveis pela formação das paredes celulares de grãos e plantas e, muitas vezes, indisponibilizam o conteúdo celular para aproveitamento pelos animais. Em suínos, a solubilidade e a digestibilidade da celulose e da hemicelulose ocorre por fermentação microbiana somente no intestino grosso, onde a degradação desses componentes contribui de maneira insignificante para sua utilização. Neste caso, a utilização da xilanase nas dietas pode aumentar a digestibilidade dos nutrientes, armazenados entre as camadas de polissacarídeos não amiláceos dos alimentos de origem vegetal (Bedford, 2000).

A variabilidade nos resultados de digestibilidade ileal pode ser determinada por vários fatores que envolvem não só a presença e o tipo de fatores antinutricionais, mas também a quantidade destes fatores (Kies et al., 2001). $\mathrm{Na}$ literatura, inúmeros estudos têm abordado os efeitos da adição da fitase e da xilanase, muitos deles de forma isolada, sobre a digestibilidade dos nutrientes em suínos.

Em virtude da variabilidade nos resultados experimentais, é interessante a aplicação da meta-análise, pois permite integrar diferentes variáveis e estabelecer respostas ajustadas à diversidade experimental (Sauvant et al., 2008).

O objetivo deste trabalho foi avaliar, por meio de meta-análise, os efeitos da adição da fitase e da xilanase às dietas sobre a digestibilidade ileal aparente dos aminoácidos, do cálcio e do fósforo, em suínos em crescimento.

\section{Material e Métodos}

Os artigos que compuseram a base de dados tiveram como principais critérios de seleção: a adição de fitase de origem fúngica e xilanase às dietas; a avaliação de suínos em crescimento; o método de coleta ileal por cânula $T$ simples e resultados de digestibilidade ileal aparente de aminoácidos, cálcio e fósforo. Para a maior qualidade metodológica dos estudos, durante a fase de seleção e de análise dos resultados, consideraram-se artigos publicados em periódicos, com fator de impacto acima de 1,4 , referentes aos últimos cinco anos.

Os dados foram selecionados das seções material e métodos e resultados, de cada artigo, e tabuladas em uma base de dados elaborada em planilha eletrônica. As variáveis analisadas foram relacionadas à composição nutricional e aos níveis de inclusão de cereais nas dietas e aos efeitos da fitase e xilanase sobre a digestibilidade ileal aparente de aminoácidos, cálcio e fósforo. A metodologia para a definição das variáveis dependentes e independentes e a codificação dos dados seguiram as proposições descritas na literatura (Lovatto et al., 2007; Sauvant et al., 2008).

A ausência ou presença de enzimas fitase $\mathrm{e}$ xilanase foram utilizadas como critérios qualitativos de agrupamento, como recurso para associar grupos homogêneos em determinados critérios, e para incluí-los nos modelos analíticos como fonte de variação. Outras codificações foram utilizadas como variáveis moderadoras nas análises, com o objetivo de considerar a variabilidade dos estudos compilados (efeito do estudo, efeitos inter e intraestudos). Para a codificação geral do artigo, foi atribuído um número sequencial específico para cada trabalho inserido na base. A codificação inter foi formada pela união da codificação geral e de números sequenciais, de maneira a atribuir um código específico para cada tratamento da base. A codificação intra, semelhante à utilizada para análise do efeito anterior, foi atribuída aos grupos com medidas repetidas.

A base de dados totalizou 21 artigos, publicados em periódicos internacionais entre 1998 e 2009 (moda: 2008), dos quais 12 avaliaram fitase e 9 avaliaram xilanase (Valaja et al., 1998; Kemme et al., 1999; Selle et al., 2000; Yin et al., 2000a, 2000b; Jondreville et al., 2001; Kies et al., 2001; Traylor et al., 2001; Barrera et al., 2004; Cervantes et al., 2004; Liao et al., 2005; Lyberg et al., 2006; Nyachoti et al., 2006; Radcliffe et al., 2006; Lindberg et al., 2007; Nortey et al., 2007, 2008; Pomar et al., 2008; Woyengo et al., 2008, 2009; Sands et al., 2009). A maior parte destes artigos foi publicada nos periódicos Journal of Animal Science, Livestock Production Science, Animal Feed Science and Technology e Animal Science. Os experimentos foram realizados em instituições canadenses (40\%), européias (30\%) e americanas (25\%). A base foi composta de 133 dietas e 82 tratamentos, no total de 644 machos castrados, com média de cinco animais por tratamento. Os pesos dos animais, ao início e final dos experimentos, foram de 33,9 $\pm 15,9$ e $65,8 \pm 18,9 \mathrm{~kg}$, respectivamente. Os delineamentos experimentais utilizados foram o quadrado latino (70\%) e blocos ao acaso (30\%). Em todos os trabalhos, os animais foram mantidos em observação, em média, por 
14 dias (variação de 5 a 21 dias) após a cirurgia ileocecal. O período de adaptação dos animais ao ambiente e ao alimento foi em média de 6,6 dias (4 a 10 dias). O período destinado à coleta ileal foi em média de 38 horas (12 a 96 horas). Aduração média dos experimentos foi de 37 dias (20 a 70 dias). Cada período experimental teve duração média de 11 dias (7 a 21 dias). Os animais utilizados nos experimentos foram híbridos comerciais, com peso médio de 44,9 kg (24 a $64 \mathrm{~kg}$ ) e 72 dias de idade ao início (43 a 135 dias) e 113 dias ao final dos experimentos (65 a 170 dias).

Em todos os trabalhos, as exigências nutricionais foram estabelecidas de acordo com o National Research Council (1998). Os principais ingredientes utilizados nas dietas e suas estatísticas descritivas estão apresentados na Tabela 1. Os estudos com fitase apresentaram níveis médios de 850 unidades $\mathrm{kg}^{-1}$ de dieta (250 a 1.600 unidades $\mathrm{kg}^{-1}$ de dieta). No presente trabalho, foram selecionados somente artigos sobre fitase fúngica, proveniente de cepas de Aspergillus, em decorrência do maior número de trabalhos publicados sobre essa enzima. Os níveis de xilanase estudados apresentaram valores médios de 4.858 unidades $\mathrm{kg}^{-1}$ de dieta $(2.000$ a 16.500 unidades $\mathrm{kg}^{-1}$ de dieta). $\mathrm{O}$ fornecimento das dietas foi controlado em $60 \%$ dos trabalhos e os animais tiveram livre acesso à água em todos os experimentos.

A meta-análise constituiu-se de três análises sequenciais: gráfica, para controlar a qualidade da base e observar a coerência biológica dos dados; de correlação entre as diversas variáveis, para identificar os fatores relacionados na base; e de variância-covariância. Foram utilizados, nos modelos para as análises de variânciacovariância, os fatores com coeficientes de correlação mais elevados e as codificações para os efeitos inter ou intraestudos (Lovatto et al., 2007). As equações de regressão foram obtidas por meio da análise de variância-covariância pelo procedimento GLM. Todas

Tabela 1. Principais ingredientes e composição calculada das dietas de suínos em crescimento utilizadas nos estudos.

\begin{tabular}{|c|c|c|c|c|c|}
\hline Variável & № de dietas & Média & Mínimo & Máximo & Desvio-padrão \\
\hline \multicolumn{6}{|l|}{ Ingredientes (\%) } \\
\hline Milho & 60 & 60,75 & 20,00 & 87,54 & 23,84 \\
\hline Trigo & 57 & 56,60 & 5,00 & 83,26 & 15,65 \\
\hline Cevada & 17 & 29,36 & 10,00 & 29,00 & 15,31 \\
\hline Farelo de soja & 133 & 14,15 & 3,10 & 35,45 & 7,70 \\
\hline \multicolumn{6}{|l|}{ Composição calculada } \\
\hline Energia digestível $\left(\mathrm{kcal} \mathrm{kg}^{-1}\right)$ & - & 3.338 & 3.283 & 3.390 & 68,31 \\
\hline Energia metabolizável $\left(\mathrm{kcal} \mathrm{kg}^{-1}\right)$ & - & 3.365 & 3.265 & 3.506 & 70,22 \\
\hline Proteína bruta (\%) & - & 16,33 & 14,64 & 18,34 & 2,71 \\
\hline Cálcio (\%) & - & 0,55 & 0,40 & 0,90 & 0,13 \\
\hline Fósforo total (\%) & - & 0,48 & 0,23 & 0,86 & 0,10 \\
\hline Fósforo disponível (\%) & - & 0,23 & 0,09 & 0,61 & 0,11 \\
\hline \multicolumn{6}{|l|}{ Aminoácidos (\%) } \\
\hline Alanina & - & 0,80 & 0,62 & 1,08 & 0,09 \\
\hline Arginina & - & 0,85 & 0,16 & 1,20 & 0,21 \\
\hline Cistina & - & 0,51 & 0,25 & 0,96 & 0,26 \\
\hline Fenilalanina & - & 0,67 & 0,40 & 0,97 & 0,14 \\
\hline Glicina & - & 1,03 & 0,52 & 3,64 & 0,74 \\
\hline Histidina & - & 0,46 & 0,14 & 1,53 & 0,34 \\
\hline Isoleucina & - & 0,59 & 0,22 & 0,83 & 0,13 \\
\hline Leucina & - & 1,12 & 0,43 & 1,41 & 0,26 \\
\hline Lisina & - & 0,85 & 0,38 & 1,19 & 0,17 \\
\hline Metionina & - & 0,29 & 0,14 & 0,98 & 0,22 \\
\hline Prolina & - & 1,37 & 0,69 & 1,64 & 0,25 \\
\hline Serina & - & 0,85 & 0,49 & 0,94 & 0,12 \\
\hline Tirosina & - & 0,50 & 0,19 & 0,87 & 0,16 \\
\hline Treonina & - & 0,52 & 0,41 & 0,68 & 0,08 \\
\hline Triptofano & - & 0,23 & 0,09 & 0,69 & 0,18 \\
\hline Valina & - & 0,79 & 0,30 & 1,24 & 0,20 \\
\hline
\end{tabular}


as análises foram realizadas através do programa Minitab 15 (Minitab, 2007).

\section{Resultados e Discussão}

O nível do P fítico das dietas apresentou correlação negativa com a digestibilidade ileal aparente do cálcio e do fósforo em suínos (Tabela 2). As correlações entre o P fítico e a digestibilidade ileal dos aminoácidos foram significativas e baixas, e foram verificadas no ácido aspártico, alanina, arginina, histidina, isoleucina, lisina e metionina. A interação entre fitatos e proteínas ocorre através de ligações com resíduos básicos como a arginina, lisina e histidina formando um complexo insolúvel (Kies et al., 2001). Neste caso, a formação desses complexos no intestino pode influenciar negativamente a digestibilidade e a absorção de aminoácidos. Os fitatos, por sua vez, inibem várias enzimas digestivas como pepsina, amilase ou tripsina (Maenz, 2001). Esse mecanismo pode ser explicado pela formação de complexos quelatados - entre fitatos, minerais e aminoácidos - que comprometem a atuação dos minerais como cofatores enzimáticos, o que pode reduzir a eficiência ou até inativar enzimas no trato digestivo (Bedford, 2000).
As frações de fibra bruta apresentaram correlação negativa com a digestibilidade ileal aparente do $\mathrm{Ca}$ e $\mathrm{P}$, com os aminoácidos fenilalanina, lisina, leucina, prolina e serina. As frações de fibra em detergente neutro (FDN) apresentaram correlação negativa com a digestibilidade ileal aparente da arginina, histidina, isoleucina, lisina e metionina. A fibra em detergente ácido (FDA) apresentou correlações negativas com o ácido aspártico e glutâmico, alanina, fenilalanina e prolina. As frações de lignina em detergente ácido (LDA) apresentaram correlações negativas com o ácido glutâmico, alanina e fenilalanina. A digestibilidade ileal dos aminoácidos se reduz linearmente com o aumento dos teores de FDA em ingredientes como o trigo, milho e sorgo (Jondreville et al., 1994). Além disso, as correlações observadas no presente trabalho corroboram os resultados obtidos em outros trabalhos (Jondreville et al., 1994, 2001). A redução nos valores da digestibilidade ileal é explicada, em parte, pelo aumento na excreção de nitrogênio endógeno, à medida que aumentam os teores de fibra na dieta (Yin et al., 2000a; Huang et al., 2001). Diversos fatores interferem na digestibilidade dos aminoácidos em suínos, entre eles o tipo de cereal utilizado na dieta, o nível de P fítico, a localização dos aminoácidos nos grãos e o efeito que as fibras exercem sobre os aminoácidos (Jondreville

Tabela 2. Correlações da digestibilidade ileal aparente (\%) de nutrientes com o P fítico e as frações de fibra ( $\left.\mathrm{g} \mathrm{kg}^{-1}\right)$, em dietas de suínos em crescimento.

\begin{tabular}{|c|c|c|c|c|c|}
\hline Nutriente & $\mathrm{P}$ fítico & FB & FDN & FDA & LDA \\
\hline Cálcio & $-0,255^{*}$ & $-0,181^{*}$ & $-0,052^{\mathrm{ns}}$ & $0,075^{\mathrm{ns}}$ & $-0,009^{n s}$ \\
\hline Fósforo & $-0,521 *$ & $-0,231 * *$ & $0,019^{\text {ns }}$ & $0,217^{*}$ & $0,004^{\mathrm{ns}}$ \\
\hline Ácido aspártico & $-0,235 * *$ & $0,034^{\mathrm{ns}}$ & $-0,134^{\mathrm{ns}}$ & $-0,262 * *$ & $0,199 *$ \\
\hline Ácido glutâmico & $0,010^{\mathrm{ns}}$ & $-0,308 * *$ & $-0,045^{\mathrm{ns}}$ & $-0,281 * *$ & $-0,307 * *$ \\
\hline Alanina & $-0,198 * *$ & $0,117^{\mathrm{ns}}$ & $-0,063^{\mathrm{ns}}$ & $-0,233 * *$ & $-0,287^{* *}$ \\
\hline Arginina & $-0,274 * *$ & $-0,146^{\mathrm{ns}}$ & $-0,155^{*}$ & $-0,109^{\mathrm{ns}}$ & $0,016^{\mathrm{ns}}$ \\
\hline Cistina & $-0,220^{*}$ & $-0,013^{\mathrm{ns}}$ & $0,086^{\mathrm{ns}}$ & $0,068^{\mathrm{ns}}$ & $0,074^{\mathrm{ns}}$ \\
\hline Fenilalanina & $0,020^{\mathrm{ns}}$ & $-0,223 * *$ & $0,028^{\mathrm{ns}}$ & $-0,233 * *$ & $-0,262 * *$ \\
\hline Glicina & $0,033^{\mathrm{ns}}$ & $-0,070^{\mathrm{ns}}$ & $0,095^{\mathrm{ns}}$ & $-0,062^{\mathrm{ns}}$ & $-0,059^{\mathrm{ns}}$ \\
\hline Histidina & $-0,238 * *$ & $-0,119^{\mathrm{ns}}$ & $-0,194 *$ & $0,046^{\mathrm{ns}}$ & $-0,006^{\mathrm{ns}}$ \\
\hline Isoleucina & $-0,338 * *$ & $0,129^{\mathrm{ns}}$ & $-0,200^{*}$ & $0,011^{\mathrm{ns}}$ & $0,063^{\mathrm{ns}}$ \\
\hline Leucina & $-0,119^{\mathrm{ns}}$ & $-0,164 *$ & $-0,082^{\mathrm{ns}}$ & $0,079^{\mathrm{ns}}$ & $-0,060^{\mathrm{ns}}$ \\
\hline Lisina & $-0,278 * *$ & $-0,155^{*}$ & $-0,198 *$ & $-0,051^{\mathrm{ns}}$ & $-0,007^{\mathrm{ns}}$ \\
\hline Metionina & $-0,265^{* *}$ & $-0,017^{\mathrm{ns}}$ & $-0,177^{*}$ & $0,171^{\mathrm{ns}}$ & $0,172^{\mathrm{ns}}$ \\
\hline Prolina & $0,077^{\mathrm{ns}}$ & $-0,199 * *$ & $0,124^{\mathrm{ns}}$ & $-0,265^{* *}$ & $-0,272 * *$ \\
\hline Tirosina & $-0,023^{\mathrm{ns}}$ & $-0,004^{\mathrm{ns}}$ & $0,036^{\mathrm{ns}}$ & $0,060^{\mathrm{ns}}$ & $0,033^{\mathrm{ns}}$ \\
\hline Treonina & $-0,169^{*}$ & $-0,149^{\mathrm{ns}}$ & $-0,110^{\mathrm{ns}}$ & $-0,039^{\mathrm{ns}}$ & $-0,031^{\mathrm{ns}}$ \\
\hline Serina & $-0,141^{\mathrm{ns}}$ & $-0,177 *$ & $-0,137^{\mathrm{ns}}$ & $0,039^{\mathrm{ns}}$ & $-0,053^{\mathrm{ns}}$ \\
\hline Valina & $-0,170^{*}$ & $-0,079^{\mathrm{ns}}$ & $-0,082^{\mathrm{ns}}$ & $0,115^{\mathrm{ns}}$ & $0,068^{\mathrm{ns}}$ \\
\hline
\end{tabular}

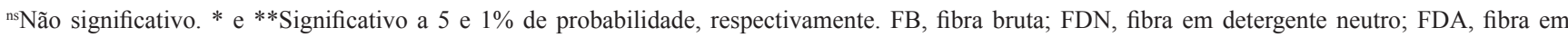
detergente ácido; LDA, lignina em detergente ácido. 
et al., 1994). Os resultados obtidos pela meta-análise indicam que esses componentes tem influência sobre a digestibilidade ileal dos nutrientes, e é necessário considerar, ainda, a interferência de outros fatores.

$A$ adição de fitase às dietas aumentou em $2 \%$ a digestibilidade ileal aparente da arginina em suínos (Tabela 3). Em pH ácido, resíduos de arginina interagem com as cargas negativas dos grupos fosfato da molécula de fitato, formam complexos aminoácido-fitato (Selle \& Ravindran, 2007). No entanto, o radical fosfato compete com um radical guanidina, presente na arginina pelo sítio de ligação dos resíduos Arg-His-Gli, e deixa o complexo instável e suscetível ao ataque da fitase (Kornegay, 2001). É provável que a competição da guanidina com o radical fosfato tenha reduzido a formação de complexos entre moléculas de fitato e o radical arginina e tenha melhorado a eficiência da fitase sobre ligações de arginina-fosfato.

A digestibilidade ileal da arginina, fenilalanina, isoleucina e lisina foi 3,3\% superior em suínos alimentados com dietas que continham xilanase, em comparação às dietas sem a enzima (Tabela 3). Além disso, a digestibilidade ileal aparente da alanina e histidina foi 5 e $4 \%$ superior, em suínos alimentados com dietas que continham xilanase, em comparação aos que se alimentaram com dietas sem a enzima. Entre os aminoácidos não essenciais, a xilanase aumentou em $3 \%$ a digestibilidade ileal aparente do ácido glutâmico, $6 \%$ a digestibilidade ileal aparente da serina, $7 \%$ da glicina e $11 \%$ da tirosina.Adigestibilidade dos nutrientes pode ser modulada pelas características inerentes a cada ingrediente ou pela presença de fibra na dieta (Yin et al., 2000a; Sands et al., 2009). Altos teores de PNAs nos ingredientes aumentam a viscosidade do quimo. Além disso, polímeros de arabinose, que são solúveis no trato gastrintestinal, interagem com outros polímeros, o que resulta na formação do bolo alimentar viscoso (Barrera et al, 2004). A viscosidade do quimo implica a queda da atividade enzimática sobre o substrato e diminui a digestibilidade dos nutrientes (Partridge, 2001). A xilanase hidrolisa as arabinoxilanas e reduz a formação destes polímeros, o que faz aumentar a quantidade de substrato disponível para as enzimas digestivas (Barrera et al., 2004). Esse mecanismo pode explicar, em parte, o aumento observado na digestibilidade ileal dos aminoácidos. Além disso, a ação da xilanase pode variar entre aminoácidos, uma vez que a quantidade de polissacarídeos não amiláceos na dieta altera a amplitude das respostas (Yin et al., 2000a; Barrera et al., 2004).

Os resultados da digestibilidade ileal aparente de metionina, valina, alanina, cistina, glicina, prolina e

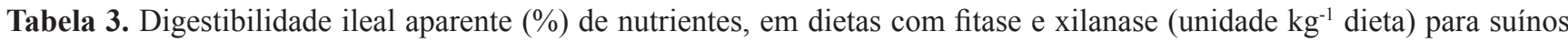
em crescimento.

\begin{tabular}{|c|c|c|c|c|c|c|c|c|c|c|}
\hline \multirow[t]{2}{*}{ Nutriente } & \multicolumn{5}{|c|}{ Fitase } & \multicolumn{5}{|c|}{ Xilanase } \\
\hline & Sem & Com & Dpr & $\mathrm{R}^{2}$ & $\mathrm{P}$ & Sem & Com & Dpr & $\mathrm{R}^{2}$ & $\mathrm{P}$ \\
\hline Cálcio & 52,1 & 59,7 & 5,6 & 0,71 & $* *$ & 49,4 & 55,9 & 6,6 & 0,24 & * \\
\hline Fósforo & 35,6 & 47,8 & 8,2 & 0,69 & $* *$ & 32,5 & 33,1 & 8,2 & 0,44 & ns \\
\hline Ácido aspártico & 75,5 & 76,9 & 2,1 & 0,86 & ns & 67,7 & 69,6 & 5,5 & 0,74 & ns \\
\hline Ácido glutâmico & 84,6 & 85,6 & 1,4 & 0,92 & ns & 84,7 & 87,3 & 3,5 & 0,56 & $*$ \\
\hline Alanina & 72,8 & 75,0 & 3,1 & 0,82 & ns & 65,1 & 68,4 & 5,0 & 0,61 & $*$ \\
\hline Arginina & 84,2 & 85,9 & 1,6 & 0,93 & $* *$ & 83,6 & 86,2 & 2,6 & 0,58 & ** \\
\hline Cistina & 74,0 & 74,8 & 2,6 & 0,81 & ns & 65,6 & 67,9 & 5,6 & 0,77 & $\mathrm{~ns}$ \\
\hline Fenilalanina & 80,5 & 81,4 & 1,9 & 0,81 & ns & 80,1 & 83,4 & 3,4 & 0,63 & ** \\
\hline Glicina & 65,4 & 67,3 & 3,9 & 0,86 & ns & 60,5 & 64,7 & 6,4 & 0,68 & * \\
\hline Histidina & 80,6 & 81,4 & 1,5 & 0,84 & ns & 78,0 & 81,0 & 3,7 & 0,58 & * \\
\hline Isoleucina & 78,6 & 79,9 & 2,0 & 0,81 & ns & 76,8 & 79,5 & 2,8 & 0,49 & ** \\
\hline Leucina & 80,7 & 81,7 & 1,7 & 0,85 & ns & 78,8 & 79,5 & 3,0 & 0,44 & $*$ \\
\hline Lisina & 78,8 & 78,9 & 2,0 & 0,89 & ns & 76,6 & 79,1 & 4,2 & 0,80 & $* *$ \\
\hline Metionina & 80,8 & 82,1 & 1,7 & 0,81 & ns & 74,3 & 76,2 & 4,0 & 0,82 & ns \\
\hline Prolina & 73,8 & 74,4 & 2,9 & 0,97 & ns & 79,4 & 81,3 & 6,1 & 0,47 & ns \\
\hline Serina & 75,7 & 76,7 & 1,9 & 0,92 & ns & 70,4 & 74,7 & 5,2 & 0,62 & * \\
\hline Tirosina & 79,2 & 80,3 & 2,1 & 0,81 & ns & 72,3 & 81,7 & 13,4 & 0,24 & * \\
\hline Treonina & 70,3 & 71,5 & 2,5 & 0,86 & ns & 66,8 & 69,6 & 6,7 & 0,62 & ns \\
\hline Valina & 75,7 & 77,2 & 2,2 & 0,80 & ns & 72,7 & 76,2 & 5,2 & 0,31 & ns \\
\hline
\end{tabular}

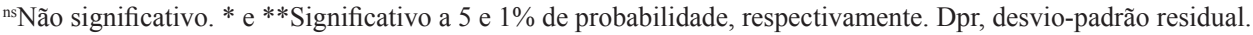


tirosina de suínos, alimentados com dietas com fitase (850 unidades $\mathrm{kg}^{-1}$ dieta) (Tabela 4), corroboram os obtidos em estudos com dietas que continham níveis superiores a 500 unidades $\mathrm{gg}^{-1}$ de fitase, o que corresponde a acréscimo de 1 a 2\% (Kemme et al., 1999) e de até $8 \%$ (Radcliffe et al., 2006) na digestibilidade ileal dos aminoácidos. Nos ingredientes, o $\mathrm{P}$ fítico pode formar complexos fitato-proteína. No trato gastrintestinal, pode ocorrer nova formação de complexos com aminoácidos livres, além da formação de complexos entre fitato e enzimas proteolíticas (Kies et al., 2001). A melhor digestibilidade dos aminoácidos, em suínos alimentados com dietas com fitase, pode ser explicada pela ação direta da enzima sobre o fitato que reduz a formação de complexos. No entanto, os efeitos da fitase sobre a digestibilidade dos aminoácidos ainda é contraditório (Cervantes et al., 2004; Nortey et al., 2007).

Em dietas que contêm xilanase, a digestibilidade dos aminoácidos aumenta em média $3 \%$ com a adição de 4.858 unidades $\mathrm{kg}^{-1}$ (Tabela 4). As equações obtidas confirmam que a ação da xilanase aumenta a digestibilidade ileal dos aminoácidos essenciais e não essenciais em 2 a 3\%. No entanto, os estudos indicam variações quanto aos aminoácidos que apresentam melhor digestibilidade ileal aparente (Yin et al., 2000a; Barrera et al., 2004; Nortey et al., 2008; Woyengo et al.,
2008). Um dos mecanismos de ação da xilanase sobre a digestibilidade dos aminoácidos está relacionado à redução da barreira física entre enzimas e substrato (Yin et al., 2000b). Com a ação da xilanase sobre as arabinoxilanas e as $\beta$-glucanas ocorre a redução na viscosidade do quimo, o que possibilita maior atividade das enzimas endógenas sobre o subtrato.

As equações que melhor explicaram a digestibilidade ileal aparente do $\mathrm{Ca}$ e $\mathrm{P}$ são as que tiveram como covariáveis, além dos níveis de enzimas, o peso vivo e os níveis nutricionais de $\mathrm{Ca}$ e $\mathrm{P}$ nas dietas (Tabela 5). Não foram observadas interferências de aminoácidos sobre a digestibilidade ileal aparente do $\mathrm{Ca}$ e $\mathrm{P}$ por meio de equações de variância-covariância. A fitase foi responsável pelo aumento da digestibilidade ileal aparente do $\mathrm{Ca}$ e do P. A atividade da fitase sobre o $\mathrm{P}$ fítico no estômago reduz a quantidade de fitatos livres, que podem se complexar com os íons de $\mathrm{Ca}$ no intestino delgado (Kornegay, 2001). O aumento da digestibilidade ileal do P pela fitase, indiretamente, aumenta a digestibilidade ileal do cálcio (Bohlke et al., 2005). No presente trabalho, esse aumento foi confirmado pela correlação positiva entre a digestibilidade ileal aparente do $\mathrm{Ca}$ e do $\mathrm{P}$ com os níveis de fitase estudados. Foi observado, também, aumento de $14 \%$ na digestibilidade ileal aparente do

Tabela 4. Equações para estimar a digestibilidade ileal aparente (DIa) de aminoácidos, em dietas com fitase e xilanase para suínos em crescimento.

\begin{tabular}{|c|c|c|c|c|c|c|}
\hline Aminoácido & Intercepto & Enzima & Dpr & $\mathrm{R}^{2}$ & DIa $(\%)^{(1)}$ & Aminoácido $\left(\mathrm{g} \mathrm{kg}^{-1}\right)^{(2)}$ \\
\hline Alanina & 69,04 & 0,00785 fitase & 2,49 & 0,92 & 6,68 & 0,53 \\
\hline Cistina & 75,96 & 0,00528 fitase & 1,84 & 0,81 & 4,49 & 0,23 \\
\hline Glicina & 69,66 & 0,00829fitase & 1,57 & 0,95 & 7,05 & 0,72 \\
\hline Metionina & 82,71 & 0,00401fitase & 1,20 & 0,89 & 3,41 & 0,11 \\
\hline Prolina & 82,83 & 0,00955 fitase & 2,49 & 0,91 & 8,12 & 1,11 \\
\hline Tirosina & 80,29 & 0,00187 fitase & 2,09 & 0,79 & 1,59 & 0,08 \\
\hline Valina & 76,43 & 0,00646 fitase & 1,24 & 0,92 & 5,49 & 0,43 \\
\hline$\overline{\text { Alanina }}$ & 65,98 & 0,00061 xilase & 5,09 & 0,59 & 2,99 & 0,24 \\
\hline Arginina & 83,72 & $0,00045 x i l a s e$ & 3,11 & 0,35 & 2,22 & 0,20 \\
\hline Fenilalanina & 82,90 & $0,00053 x i l a s e$ & 4,22 & 0,41 & 2,58 & 0,19 \\
\hline Glicina & 65,21 & 0,00089xilase & 7,46 & 0,52 & 4,32 & 0,44 \\
\hline Histidina & 79,70 & $0,00046 x$ xilase & 3,72 & 0,50 & 2,26 & 0,10 \\
\hline Leucina & 79,55 & 0,00049xilase & 3,12 & 0,36 & 2,38 & 0,28 \\
\hline Isoleucina & 77,52 & $0,00044 x i l a s e$ & 3,24 & 0,35 & 2,16 & 0,14 \\
\hline Lisina & 77,51 & 0,00074xilase & 5,11 & 0,69 & 3,60 & 0,30 \\
\hline Prolina & 79,88 & $0,00062 x i l a s e$ & 6,00 & 0,47 & 3,01 & 0,41 \\
\hline Serina & 75,29 & $0,00065 x$ xilase & 5,70 & 0,52 & 3,17 & 0,26 \\
\hline Treonina & 69,35 & $0,00076 x$ xilase & 7,41 & 0,60 & 3,71 & 0,22 \\
\hline Valina & 74,06 & $0,00058 x$ xilase & 5,46 & 0,24 & 2,81 & 0,22 \\
\hline
\end{tabular}

(1)Estimado com base nos valores médios de fitase (850 unidades $\mathrm{kg}^{-1}$ dieta) e xilanase (4.858 unidades $\mathrm{kg}^{-1}$ dieta). (2) Quantidade de cada aminoácido que foi utilizada a mais pelo animal, com o aumento da DIa calculada pelo nível nutricional médio das dietas, multiplicado pelo aumento da DIa (\%) obtida pelas equações. Dpr, desvio-padrão residual. 
Tabela 5. Equações para estimar a digestibilidade ileal aparente $(\%)$ de $\mathrm{Ca}$ e $\mathrm{P}$, em dietas com fitase para suínos em crescimento $^{(1)}$.

\begin{tabular}{|c|c|c|c|c|}
\hline \multicolumn{2}{|c|}{ Nutriente Covariáveis ${ }^{(2)}$} & Equação & Dpr & $\mathrm{R}^{2}$ \\
\hline \multirow{3}{*}{$\mathrm{Ca}$} & Pt, Fit & $228,1+0,0092$ Fit $-320,42 \mathrm{Pt}$ & 3,22 & 0,89 \\
\hline & Fit & $48,41+0,0145$ Fit & 5,59 & 0,89 \\
\hline & Fit & $53,81+0,0075$ Fit & 5,50 & 0,78 \\
\hline & Fit, Fit $^{2}$ & $35,83+0,0370$ Fit $-0,000011$ Fit $^{2}$ & 3,99 & 0,97 \\
\hline & Fit & $43,89+0,0269$ Fit & 4,03 & 0,91 \\
\hline & PB, Fit & $97,29+0,0163$ Fit $-4,22 \mathrm{~PB}$ & 5,73 & 0,92 \\
\hline & PVi, Fit & $18,99+0,0165$ Fit $+0,457 \mathrm{PVi}$ & 5,32 & 0,92 \\
\hline & $\mathrm{Ca}$, Fit & $80,64+0,0149$ Fit $-78,81 \mathrm{Ca}$ & 6,75 & 0,87 \\
\hline & Pt, Fit & $67,64+60,34 \mathrm{Pt}+0,0148 \mathrm{Fit}$ & 6,89 & 0,84 \\
\hline
\end{tabular}

(1)PVi: peso vivo inicial dos animais. $\mathrm{PB}, \mathrm{Ca}$, Pt: proteína bruta, $\mathrm{Ca}$ e $\mathrm{P}$ total nas dietas, em percentagem. Fit: níveis de fitase nas dietas (unidades $\mathrm{kg}^{-1}$ dieta). ${ }^{(2)}$ Fatores considerados no modelo: tratamentos e base da dieta. Dpr, desviopadrão residual.

$\mathrm{Ca}$ e de $34 \%$ na digestibilidade ileal aparente do $\mathrm{P}$ em dietas que continham fitase.

Entre as equações obtidas no presente estudo foram verificadas interferências dos minerais $\mathrm{Ca}$ e $\mathrm{P}$ sobre a atividade da fitase na digestibilidade ileal dos nutrientes (Tabela 5). A relação Ca:P das dietas pode comprometer a ação da fitase. Níveis excessivos de $\mathrm{Ca}$ nas dietas (relações superiores a 1,6:1) podem formar complexos insolúveis com o fitato (Kornegay, 2001). A molécula de fitato permanece envolvida por íons de $\mathrm{Ca}$, o que impede a hidrólise das ligações fosfato-Ca pela fitase. A liberação de $\mathrm{P}$, por unidade de fitase, diminui com o aumento do nível de $\mathrm{P}$ na dieta. Em virtude disso, níveis extremos devem ser evitados para otimizar as respostas da fitase (Kornegay, 2001).

\section{Conclusões}

1. A presença de P fítico e de fibra nas dietas interfere negativamente na digestibilidade ileal do cálcio, do fósforo e dos aminoácidos essenciais.

2. A adição das enzimas fitase e xilanase nas dietas aumenta a digestibilidade ileal do cálcio, do fósforo e de alguns aminoácidos.

3. O excesso de $\mathrm{Ca}$ e $\mathrm{P}$ na dieta reduz a eficácia da fitase sobre a digestibilidade ileal dos nutrientes.

\section{Agradecimentos}

Ao Programa de Apoio a Planos de Reestruturação e Expansão das Universidades Federais; à Coordenação de Aperfeiçoamento de Pessoal de Nível Superior; e ao Conselho Nacional de Desenvolvimento Científico e Tecnológico, pelas bolsas concedidas.

\section{Referências}

BARRERA, M.; CERVANTES, M.; SAUER, W.C.; ARAIZA, A.B.; TORRENTERA, N. Ileal amino acid digestibility and performance of growing pigs fed wheat-based diets supplemented with xylanase. Journal of Animal Science, v.82, p.1997-2003, 2004.

BEDFORD, M.R. Exogenous enzymes in monogastric nutrition their current value and future benefits. Animal Feed Science and Technology, v.86, p.1-13, 2000.

BOHLKE, R.A.; THALER, R.C.; STEIN, H.H. Calcium, phosphorus, and amino acid digestibility in low-phytate corn, normal corn, and soybean meal by growing pigs. Journal of Animal Science, v.83, p.2396-2403, 2005.

CERVANTES, M.; YÁNEZ, J.; BARRERA, M.A.; FIGUEROA, J.L.; TORRENTERA, N.; SAUER, W. Leal amino acid digestibility and performance of pigs fed grain sorghum-based diets supplemented with phytase. Interciencia, v.29, p.527-531, 2004.

HUANG, S.X.; SAUER, W.C.; MARTY, B. Ileal digestibilities of neutral detergent fiber, crude protein and amino acids associated with neutral detergent fiber in wheat shorts for growing pigs. Journal of Animal Science, v.79, p.2388-2396, 2001.

JONDREVILLE, C.; VAN DEN BROECKE, J.; DELPECH, A.; GATEL, F.; BERTIN, J.M.; BEAUX, M.F.; GROSJEAN, F. Facteurs de variation de la digestibilité iléale des acides amines des cereals chez le porc charcutier. Journées Recherche Porcine en France, v.26, p.251-258, 1994.

JONDREVILLE, C.; VAN DEN BROECKE, J.; GATEL, F.; GROSJEAN, F.; VAN CAUWENBERGHE, S.; SÈVE, B. Ileal digestibility of amino acids and estimates of endogenous amino acid losses in pigs fed wheat, triticale, rye, barley, maize and sorghum. Animal Research, v.50, p.119-134, 2001.

KEMME, P.A.; JONGBLOED, A.W.; MROZ, Z.; KOGUT, J.; BEYNEN, A.C. Digestibility of nutrients in growing-finishing pigs is affected by Aspergillus niger phytase, phytate and lactic acid levels: 1. Apparent ileal digestibility of amino acids. Livestock Production Science, v.58, p.107-117, 1999.

KIES, A.K.; VAN HEMERT, K.H.F.; SAUER, W.C. Effect of phytase on protein and amino acid digestibility and energy utilisation. World's Poultry Science Journal, v.57, p.110-126, 2001.

KORNEGAY, E.T. Digestion of phosphorus and other nutrients: the role of phytases and factors influencing their activity. In: BEDFORD, M.R.; PARTRIDGE, G.G. (Ed.). Enzymes in farm animal nutrition. Wallingford: CABI Publishing, 2001. p.237-271.

LIAO, S.F.; KIES, A.K.; SAUER, W.C.; ZHANG, Y.C.; CERVANTES, M.; HE, J.M. Effect of phytase supplementation to a low- and a high-phytate diet for growing pigs on the digestibilities of crude protein, amino acids, and energy. Journal of Animal Science, v.83, p.2130-2136, 2005.

LINDBERG, J.E.; LYBERG, K.; SANDS, J.; BAILLEUL, P.J. Influence of phytase and xylanase supplementation of a wheat-based 
diet on ileal and total tract digestibility in growing pigs. Livestock Science, v.109, p.268-270, 2007.

LOVATTO, P.A.; LEHNEN, C.R.; ANDRETTA, I.; HAUSCHILD, L.; CARVALHO, A.D. Meta-análise em pesquisas científicas - enfoque em metodologias. Revista Brasileira de Zootecnia, v.36, p.285-294, 2007.

LYBERG, K.; LUNDH, T.; PEDERSEN, C.; LINDBERG, J.E. Influence of soaking, fermentation and phytase supplementation on nutrient digestibility in pigs offered a grower diet based on wheat and barley. Animal Science, v.82, p.853-858, 2006.

MAENZ, D.D. Enzymatic characteristics of phytases as they relate to their use in animal feeds In: BEDFORD, M.R.; PARTRIDGE, G.G. (Ed.). Enzymes in farm animal nutrition. Wallingford: CABI Publishing, 2001. p.406-436.

MINITAB. User's guide: Meet Minitab. Version 15. Stat College: Minitab, 2007. 142p.

NATIONAL RESEARCH COUNCIL. Committee on Animal Nutrition. Nutrient requirements of swine. $10^{\text {th }}$.ed. Washington: National Academy of Sciences 1998. 189p.

NORTEY, T.N.; PATIENCE, J.F.; SANDS, J.S.; TROTTIER, N.L.; ZIJLSTRA, R.T. Effects of xylanase supplementation on the apparent digestibility and digestible content of energy, amino acids, phosphorus, and calcium in wheat and wheat by-products from dry milling fed to grower pigs. Journal of Animal Science, v.86, p.3450-3464, 2008.

NORTEY, T.N.; PATIENCE, J.F.; SIMMINS, P.H.; TROTTIER, N.L.; ZIJLSTRA, R.T. Effects of individual or combined xylanase and phytase supplementation on energy, amino acid, and phosphorus digestibility and growth performance of grower pigs fed wheat-based diets containing wheat millrun. Journal of Animal Science, v.85, p.1432-1443, 2007.

NYACHOTI, C.M.; ARNTFIELD, S.D.; GUENTER, W.; CENKOWSKI, S.; OPAPEJU, F.O. Effect of micronized pea and enzyme supplementation on nutrient utilization and manure output in growing pigs. Journal of Animal Science, v.84, p.2150-2156, 2006.

PARTRIDGE, G.G. The role and efficacy of carbohydrase enzymes in pig nutrition. In: BEDFORD, M.R.; PARTRIDGE, G.G. (Ed.). Enzymes in farm animal nutrition. Wallingford: CABI Publishing, 2001. p.161-198.

POMAR, C.; GAGNE, F.; MATTE, J.J.; BARNETT, G.; JONDREVILLE, C. The effect of microbial phytase on true and apparent ileal amino acid digestibilities in growing-finishing pigs. Journal of Animal Science, v.86, p.1598-1608, 2008.

RADCLIFFE, J.S.; PLEASANT, R.S.; KORNEGAY, E.T. Estimating equivalency values of microbial phytase for amino acids in growing and finishing pigs fitted with steered ileo-cecal cannulas. Journal of Animal Science, v.84, p.1119-1129, 2006.
SANDS, J.S.; RAGLAND, D.; DILGER, R.N.; ADEOLA, O. Responses of pigs to Aspergillus niger phytase supplementation of low-protein or high-phytin diets. Journal of Animal Science, v.87, p.2581-2589, 2009.

SAUVANT, D.; SCHMIDELY, P.; DAUDIN, J.J.; ST-PIERRE, N.R. Meta-analyses of experimental data in animal nutrition. Animal, v.2, p.1203-1214, 2008.

SELLE, P.H.; RAVINDRAN, V. Microbial phytase in poultry nutrition. Animal Feed Science and Technology, v.135, p.1-41, 2007.

SELLE, P.H.; RAVINDRAN, V.; CALDWELL, R.A.; BRYDEN, W.L. Phytate and phytase: consequences for protein utilisation. Nutrition Research Reviews, v.13, p.255-278, 2000.

TRAYLOR, S.L.; CROMWELL, G.L.; LINDEMANN, M.D.; KNABE, D.A. Effects of level of supplemental phytase on ileal digestibility of amino acids, calcium, and phosphorus in dehulled soybean meal for growing pigs. Journal of Animal Science, v.79, p.2634-2642, 2001.

VALAJA, J.; PLAAMI, S.; SILJANDER-RASI, H. Effect of microbial phytase on digestibility and utilisation of phosphorus and protein in pigs fed wet barley protein with fibre. Animal Feed Science and Technology, v.72, p.221-233, 1998.

VEUM, T.L.; ELLERSIECK, M.R. Effect of low doses of corn-soybean meal diets deficient in available phosphorus and calcium, bone strength, and nutrient absorption and excretion by growing and finishing swine fed corn-soybean meal diets deficient in available phosphorus and calcium. Journal of Animal Science, v.86, p.858-870, 2008.

WOYENGO, T.A.; DICKSON, T.; SANDS, J.S.; NYACHOTI, C.M. Nutrient digestibility in finishing pigs fed phytase-supplemented barley-based diets containing soybean meal or canola meal as a protein source. Archives of Animal Nutrition, v.63, p.137-148, 2009.

WOYENGO, T.A.; SANDS, J.S.; GUENTER, W.; NYACHOTI, C.M. Nutrient digestibility and performance responses of growing pigs fed phytase- and xylanase-supplemented wheat-based diets. Journal of Animal Science, v.86, p.848-857, 2008.

YIN, Y.-L.; MCEVOY, J.D.G.; SCHULZE, H.; HENNIG, U.; SOUFFRANT, W.-B.; MCCRACKEN, K.J. Apparent digestibility (ileal and overall) of nutrients and endogenous nitrogen losses in growing pigs fed wheat (var. Soissons) or its by-products without or with xylanase supplementation. Livestock Production Science, v.62, p.119-132, 2000a.

YIN, Y.-L.; MCEVOY, J.D.G.; SCHULZE, H.; HENNIG, U.; SOUFFRANT, W.-B.; MCCRACKEN, K.J. Apparent digestibility (ileal and overall) of nutrients as evaluated with PVTC-cannulated or ileo-rectal anastomised pigs fed diets containing two indigestible markers. Livestock Production Science, v.62, p.133-141, 2000 b.

Recebido em 7 de novembro de 2010 e aprovado em 9 de março de 2011 